\title{
Seasonal herding practices influence predation on domestic stock by African lions along a protected area boundary
}

Timothy R. Kuiper ${ }^{\dagger 1,2}$; Andrew J. Loveridge ${ }^{\dagger 2^{*}}$ Daniel M. Parker $^{1}$, Paul J. Johnson ${ }^{2}$, Jane E. Hunt $^{2}$, Brent Stapelkamp ${ }^{2}$, Lovemore Sibanda ${ }^{2}$ and David W. Macdonald ${ }^{2}$

$\dagger$ Joint first authorship

${ }^{1}$ Wildlife and Reserve Management Research Group, Department of Zoology and Entomology, P.O. Box 94, Rhodes University, Grahamstown, 6140, South Africa.

${ }^{2}$ Wildlife Conservation Research Unit, Department of Zoology, University of Oxford, Recanati-Kaplan Centre, Tubney House, Abingdon Road, Tubney, Oxfordshire OX13 5QL, UK.

*Corresponding author: A.J. Loveridge. Tel.: +44 1865 611115; fax: +44 1865 393101. Email address: andrew.loveridge@zoo.ox.ac.uk.

Running title: Livestock herding patterns influence vulnerability to lion depredation

Word count: 8349 (Total): 254 (summary), 6050 (body), 129 (acknowledgements), 1407 (references), 359 (table and figure legends).

Number of tables/figures: 0 tables, 6 Figures.

Number of references: 48 
Livestock herding patterns influence vulnerability to lion depredation

\begin{abstract}
Livestock depredation frequently results in retaliatory killing of carnivores by people. An understanding of the ecological and sociological factors that precipitate this conflict is essential to mitigation. We investigated the seasonality of lion (Panthera leo) depredation incidents in relation to cattle (Bos primigenius) herding patterns in Tsholotsho Communal Land and Ngamo Forest adjacent to Hwange National Park, Zimbabwe. Cattle from 14 villages along the protected area (PA) boundaries were fitted with GPS data loggers (2010 2012), and depredation incidents systematically recorded (2008 - 2012). More cattle were killed by lions during the wet season (October to May) than during the dry months (June to September). In the wetter months, corresponding to the growing season and the need to protect crops, cattle were herded further from their home enclosures, closer to PA boundaries and into more wooded habitats. By contrast, cattle remained closer to home, further from PAs and were left to graze in fallow fields close to villages in the dry months. Seasonal use of wooded areas distant to villages and close to PA boundaries during the growing season increases vulnerability of cattle to lion depredation. In the dry months, cattle grazing close to villages benefit from the close proximity of people, resulting in a lower incidence of depredation. Approaches to mitigate livestock depredation should focus on improving herd protection during the wet season when cattle graze far from villages. Strategies such as communal herding, more intensive livestock guarding and, where possible, avoidance of heavily wooded habitats close to PAs should be encouraged.
\end{abstract}

Key-words: carnivore conservation, herding, human-wildlife conflict, livestock, Panthera leo. 
Livestock herding patterns influence vulnerability to lion depredation

\section{Introduction}

Most large carnivore populations across the globe are declining (Inskip and Zimmermann 2009). Habitat loss and fragmentation, conflict with humans and prey depletion are all major threats (Macdonald et al. 2010). As a result of contemporary human population growth, large carnivores are becoming increasingly threatened by these pressures (Cardillo et al. 2004). An understanding of each of these threats is therefore critical to the development of effective carnivore conservation strategies.

The extensive home ranges of large carnivores and their diet predisposes them to competition with humans (Treves and Karanth 2003) and conflicts between people and wild carnivores are a global phenomenon and typically involve predators taking livestock as prey (Inskip and Zimmermann 2009). In retaliation, livestock owners often persecute (e.g. shoot, poison, snare etc.) suspected problem animals (Woodroffe and Frank 2005), such that conflict at protected area boundaries has been cited as a significant cause of mortality in large carnivore populations in protected areas (Woodroffe and Ginsberg 1998). Human encroachment into wild predator habitat, the dispersal of predators into human-dominated habitat and a high ratio of domestic to wild ungulate species all serve to elevate the intensity of conflict. In areas where depredation is perceived to adversely affect human livelihoods, lethal retaliation has the potential to impact the viability of predator populations (Loveridge et al. 2010b).

The African lion Panthera leo now occupies $8 \%$ of its historic range and between 20000 and 30000 remain on the African continent, compared to an estimated 100000 lions 40 years ago (IUCN-SSC 2006, Bauer et al. 2015). Conflict with humans over livestock is widely perceived to have played a substantial role in this decline (Woodroffe and Ginsberg 1998, 
Livestock herding patterns influence vulnerability to lion depredation

Frank et al. 2006). Along the edge of Zimbabwe's Hwange National Park (HNP), the depredation of livestock by lions leads to frequent, lethal retaliation by livestock owners amounting to $22 \%$ of recorded mortalities $(n=181,1999-2013)$. This, along with sport hunting, is the most significant source of mortality for this population (Loveridge et al. 2010a)..

Reducing livestock losses to lions is likely to lead to increased tolerance of predators and reduced retaliatory killing of lions. Therefore, understanding the factors contributing to high rates of livestock depredation is crucial. Previous studies suggest that the availability of wild prey to lions and the accessibility of domestic stock are important factors in determining depredation rates (Woodroffe and Frank 2005, Valeix et al. 2012). In this study we investigated how cattle herding patterns influence vulnerability to lion depredation in Tsholotsho Communal Land adjacent to HNP. We hypothesized that variation in landscapescale cattle herding patterns over the year is likely to affect the accessibility of cattle to lions thereby contributing to variations in vulnerability and therefore the incidence of depredation.. 
Livestock herding patterns influence vulnerability to lion depredation

\section{Materials and methods}

\subsection{Study area}

The study area spanned a $25 \mathrm{~km}$ buffer along the south-eastern border of HNP between the latitudes of $19^{0} 0$ 'S and $19^{0} 30$ 'S , constituting an area of $2930 \mathrm{~km}^{2}$ (Fig. 1). This area, part of Tsholotsho Communal Land, encompasses 3940 rural homesteads across 87 villages (Fig. 1). An informal buffer zone, between 1.5 and $8.5 \mathrm{~km}$ wide, free of settlement, but used for grazing and resource extraction, is recognised along the HNP boundary. The region is characterized by low-fertility soils (Kalahari sands) and experiences low and erratic rainfall, with an annual average of $600 \mathrm{~mm}$ and an inter-annual CV of $25 \%$. Rain falls primarily between November and March. Subsistence agro-pastoral farming practices predominate. Livestock husbandry in Zimbabwe forms an integral part of local culture and cattle are used for the production of milk and beef, and for ploughing and bartering (Hall, 1986). Seasonal crop growing (mainly maize Zea mays, but also sorghum Sorghum bicolor, millet Pennisetum glaucum and legumes Fabaceae) forms another essential component of subsistence livelihoods in the area. Traditionally, cattle graze during the day in designated grazing areas in the vicinity of villages and are brought back to the village in the evening. Cattle are not generally supervised or guarded while in grazing during the day (pers. obs.). Each village household usually has a protective enclosure (boma), constructed as a stockade of timber poles and brush wood, in which livestock are kept at night.

Ecological and agro-pastoral seasons were defined as follows and used to interpret results. (1) Ecological seasons: the wet season (November to April), and the dry season (May to October). (2) Agro-pastoral seasons: the early growing season (October to January), the late growing season (February to May) and the post-harvest season (June to September). In 
practice, the crop growing season (early and late growing and harvest seasons) largely coincides with the wet season.

Large predators present in the system included lions, spotted hyenas (Crocuta crocuta), cheetahs (Acinonyx jubatus) and leopards (Panthera pardus). Lion, hyaena and leopard occurred in the protected area immediately adjacent to the study area at densities of $4.5 / 100 \mathrm{~km}^{2}, 9.0 / 100 \mathrm{~km}^{2}$ and $1.46 / 100 \mathrm{~km}^{2}$ respectively, (Periquet 2014, Loveridge unpublished data). Cheetahs are rare in the ecosystem (pers. obs.). Predator populations were resident within the protected area with no evidence for resident populations in surrounding communal land (pers. obs.).

\subsection{Collaring of cattle}

Of 56 focal villages regularly surveyed for human-wildlife conflict incidents, 15 were randomly selected for the deployment of GPS data-logger collars (African Wildlife Tracking, Rietondale, Pretoria, South Africa). In each village, a herd of cattle was selected and a single adult female was fitted with a logger. Loggers were checked periodically to ensure they were functioning and there were no adverse effects on the study animal. Herd owners were paid a nominal fee of US\$50 for participating in the study. Each collared cow represented the movements of a herd of $25.9 \pm 15.9$ (mean \pm SD) cattle. One logger failed to collect data. Loggers were programmed to take a GPS fix every hour and were fitted to cattle for periods ranging from 15 to 20 months between April 2010 and January 2012 (516 \pm 112 days fitted, mean $\pm \mathrm{SD})$.

\subsection{Lion depredation incidents}


Between 2008 and 2012, comprehensive monitoring of livestock losses to large carnivores was carried out in Tsholotsho. Field research staff completed a survey of each village ( $\mathrm{n}=$ 56) in the study area on an approximately monthly basis, compiling reports for each conflict incident ( $n=617$ incidents). The reports included information on the date and location statistics of each incident, the predator implicated, the species and number of livestock lost, whether the incident occurred during the day or at night and whether the incident occurred within a protective enclosure (boma). Our study focused only on the incidents involving cattle and lions $(\mathrm{n}=170)$.

In order to assess the spatial relationship between conflict incidents and cattle locations, the proportion of lion-cattle conflict incidents in two different distance-to-closest-homestead categories $(0-500 \mathrm{~m},>500 \mathrm{~m})$ and distance-to-protected-area categories $(0-2.5 \mathrm{~km},>2.5 \mathrm{~km})$ was compared to the proportion of cattle GPS locations in these categories. A Chi-square goodness-of-fit analysis was run with the proportion of conflict incidents in each category as the observed distribution and the proportion of cattle locations in each category as the expected distribution. This analysis was stratified by day (06:00 - 17:00) and night (18:00 05:00).

\subsection{Seasonal cattle herding patterns}

For each of the 14 collared cows, two distance attributes were calculated for every GPS location using ArcMap 10 (ESRI 2011): (1) the distance (km) from the home enclosure and (2) the distance $(\mathrm{km})$ to the boundary of a protected area (PA, either HNP or Ngamo Forest, Fig. 1). Each collared cow was associated with a particular home enclosure throughout the study. The maximum daily distance (MDD; $\mathrm{km}$ ) travelled by each cow from its home enclosure was determined by selecting the position with the highest value for the distance 
Livestock herding patterns influence vulnerability to lion depredation

attribute by day (R Development Core Team 2012). The closest daily proximity (CDP; km) of each cow to the boundary of a PA was determined in the same way. CDP values were weighted according to the distance of each collared animal's home enclosure to the boundary of a PA (Dist) using the equation: $C D P_{A d j}=(C D P) /($ Dist $)$. This allowed for meaningful comparisons to be made between cattle from different home enclosures by accounting for the varying distances of their home enclosures from PA boundaries. Monthly variation in MDD and $\mathrm{CDP}_{A d j}$ were analysed using mixed effects analysis of variance models with type III sums of squares (Faraway 2005). Month was included as a fixed main effect, while cow identity was included as a random factor. To better fulfill model assumptions, MDD values were log transformed and $\mathrm{CDP}_{A d j}$ values were raised to a power of 1.8 according to the Box-Cox method of transformation. The effect of temporal pseudoreplication (autocorrelation) associated with repeated daily measures made on the same cow was reduced in the mixed models by randomly selecting a sample of five of the MDD or $\mathrm{CDP}_{A d j}$ values from each month and for each cow. Plots of residuals versus fitted values and q-q normal plots were used to confirm the model assumptions of homoscedasticity and normality, respectively (Faraway 2005)

Because using only the GPS fixes with maximum daily values may not account for the amount of time spent in proximity to the park boundary or distant from home enclosures, an analysis was carried out using all GPS fixes between 11.00 and 16.00 (hours of the day when cattle were likely to be actively grazing rather than travelling). The relationships between distance to homestead ( $\mathrm{DH})$ and PA ( $\mathrm{DP}_{A d j}$; using the same weighted adjustment as above) were investigated using a linear mixed model treating both cow identity and day as random factors, with day nested in cow identity. Distance from homestead (in m) was logtransformed to improve conformity with the assumptions of normal-errors models. Month 
Livestock herding patterns influence vulnerability to lion depredation

was treated as a fixed categoric factor, and hour of day as a continuous covariate. There was clear evidence for serial correlation between successive metrics within a day - we explored the pattern among lagged observations for each cow and observed positive correlations which diminished with increasing separation, but were still strong and statistically significant at four hours apart for most individuals. We therefore used the R nmle package (Pinheiro et al. 2014) to fit models with a first order autoregressive covariance structure (the 'correlation=corAR1()' option, Pinheiro \& Bates (2000)). These models were clearly a better fit to the data compared with models with uncorrelated residuals (likelihood ratio tests, $P<0.0001)$.

\subsection{Cattle movements in relation to arable fields and woody cover}

In order to test the hypothesis that seasonal cropping practices influence the movements of herded cattle, the proportion of cattle GPS fixes within arable fields was examined by month. All fields within the home ranges of the 14 collared cattle were digitized from satellite imagery (Google Earth 2013) and imported into ArcMap 10. Fields were easily identifiable from imagery and we were able to informally ground truth location of digitized arable fields through familiarity with the area. For these analyses, only daytime points recorded between 11:00 and 15:00 were used. This time period represented the time of day when cattle were most likely to be actively grazing and not moving between grazing areas and home enclosures.

In order to test for seasonal selectivity for crop fields by cows, the Jacobs' index (Jacobs 1974) was calculated for each cow and month: $D=(r-p) /(r+p-2 r p)$. The proportion of fixes within field polygons by month was used to represent site use (r), while the proportional 
area of fields within the global home ranges of the cows represented site availability (p). Global cattle home ranges were calculated using $95 \%$ fixed kernel UD estimates of all locations with least-squares cross validation in ArcMap 10 (Laver and Kelly 2008). A oneway repeated measures analysis of variance (RMANOVA) was used to test for significant difference in the Jacobs' index $(D)$ among months, with month as the within-subjects factor. The Jacobs' Index was squared to better fulfill model assumptions and the GreenhouseGeisser F-value was used to correct for departures from sphericity. To test for a relationship between selection for fields and daily cattle movements, the monthly means of MDD and $\mathrm{CDP}_{A d j}$ were modeled as a function of the Jacobs' Index using simple linear models.

The Jacobs' index was also used to test for seasonal variation in cattle habitat selectivity in relation to woody cover. Percentage woody cover at each GPS location was extracted using the MOD44B vegetation continuous fields Moderate Resolution Imaging Spectroradiometer (MODIS) imagery at 250m sub-pixel resolution (Hansen et al. 2002). The raster dataset was reclassified into four percentage woody cover categories: $0-10 \%, 10-20 \%, 20-30 \%,>30 \%$. There were few regions in the study area with $>30 \%$ cover. The analysis of woody habitat selectivity in the same way as the crop selectivity analysis above, except using the woody cover categories in place of the in/out crop field categories. Global cattle home ranges were determined in $\mathrm{R}$ using the Minimum Convex Polygon (MCP, 95\%) function in the 'adehabitatHR' package (Calenge 2006) to provide a measure of habitat availability in each cow home range. Again, only daytime (11:00 - 15:00) fixes were used.

\subsection{Seasonality in herd supervision and night-time cattle positions}

To measure the extent to which cattle were supervised when grazing in the different agricultural seasons we used data on human and cattle presence collected as part of general 
ecological monitoring of livestock and wildlife in the buffer zone between HNP and the community land. Transects were driven along sandy tracks at $10 \mathrm{~km}$ per hour with an experienced tracker seated on the front of the vehicle. Spoor (sign/ tracks) left within the last 24 hours of wild and domestic species and humans were recorded. Eighteen surveys averaging $174.14 \pm 7.97 \mathrm{~km}$ (range $136.0-214.5 \mathrm{~km}$ ) in length were undertaken between September 2007 and July 2011. Eight were in the early growing season, 3 in the late growing season and 7 in the post-harvest season. Encounter rates for humans and cattle were calculated as the number of individual spoor (tracks) per kilometer of transect driven. A proxy for the extent to which cattle were supervised by people was calculated as the ratio of humans to cattle for each survey. Variation between seasons in encounters with people, cattle and the ratio of people:cattle was tested using the Kruskal-Wallis Test.

For each collared cow, the proportion of nights spent within its home enclosure was determined by analyzing the location of GPS fixes recorded at midnight (00:00am) in relation to the home enclosure. The proportion of midnight fixes within four distance-to-homeenclosure categories was determined: 0-30m (within enclosure), 30-100m, 100m-1km and $>1 \mathrm{~km}$. Fixes within $30 \mathrm{~m}$ of the home enclosure were assumed to be in the enclosure to account for GPS data-logger error and variation in home enclosure size. GPS error was calculated for a two month period over which the loggers were stationary, using a mean point-point displacement formula. The error across all cattle was calculated as $9.5 \pm 7.2 \mathrm{~m}$ (mean \pm s.d.). Of 186 home enclosures measured in Tsholotsho, 89 were small (c. $5 \times 5 \mathrm{~m}), 90$ were medium-sized (c.10x10m) and seven were large (c. 20x20m). 
Livestock herding patterns influence vulnerability to lion depredation

\section{Results}

\subsection{Lion depredation incidents}

Between January 2008 and December 2012, 617 incidents of human-carnivore conflict were recorded in the Tsholotsho Communal Land, 170 of which involved lions as the predator and cattle as the prey $(1.6 \pm 1.1$ cattle killed per incident, mean \pm SD). More cattle were lost to lions during the growing (wet) season and fewer were lost during the postharvest (dry) season (Fig. 2). The number of cattle killed by lions between 2008 and 2012 varied significantly among months (Kruskal-Wallis, $\mathrm{H}_{(11,59)}=20.19, \mathrm{P}=0.043$ ).

Of the 170 conflict incidents, 138 included accurate records of the location statistics and timing (day/night) of the incident. More conflict incidents were recorded at night $(58 \%$, $\mathrm{N}=80)$ than during the day $(42 \%, \mathrm{~N}=58)$. In only $11(14 \%)$ of the night-time conflict incidents did lions kill cattle within their home enclosure. No cattle were attacked within their home enclosure during the day.

During the day, lions killed more cattle further $(>500 \mathrm{~m})$ from homesteads than would be expected from the low proportion of cattle GPS locations in this area category compared to areas closer to homesteads $(0-500 \mathrm{~m})\left(\right.$ Fig. $\left.3 ; \chi^{2}{ }_{(1)}=50.2, \mathrm{P}<0.01\right)$. Similarly, lions killed more cattle closer $(0-2.5 \mathrm{~km})$ to PAs than would be expected from the low proportion of cattle GPS locations in these areas compared to areas further from PAs $(>2.5 \mathrm{~km})\left(\right.$ Fig. $3 ; \chi^{2}{ }_{(1)}=65.8$, $\mathrm{P}<0.01$ ). The same pattern was true at night (Fig. 3 ; homesteads: $\chi_{(1)}^{2}=932.6, \mathrm{P}<0.01$; PAs: $\left.\chi_{(1)}^{2}=123.9, \mathrm{P}<0.01\right)$. 
Livestock herding patterns influence vulnerability to lion depredation

\subsection{Seasonal cattle herding patterns}

The maximum daily distance travelled $(\mathrm{MDD})$ by cattle varied among months $\left(\mathrm{F}_{(11,143)}=\right.$ 6.88, $\mathrm{P}<0.001$, Fig. 4) being highest in the late growing season and lowest in the post harvest season (Cow identity accounted for $7.96 \%$ of the variation in MDD (variance components analysis). Closest daily proximity $\left(\mathrm{CDP}_{A d j}\right)$ consequently also varied among months $\left(\left(\mathrm{F}_{(11,143)}=6.83, \mathrm{P}<0.001\right.\right.$, Fig 4$)$ with cattle moving closest to the park boundary in the late growing season and furthest in the post-harvest season.

The distance recorded between collared cows and their home enclosure (DH) varied significantly among months $\left(\mathrm{F}_{(11,7196)}=72.29 \mathrm{P}<0.001\right)$. Overall, cattle grazed furthest from their home enclosures in the late growing season (February to May), while remaining closer to home in the post-harvest season (June to September). The pattern of variability between months closely resembled that for MDD. We also observed a tendency for distance from homestead to decrease through the day (parameter estimate $-0.11, \mathrm{SE}=0.02, \mathrm{P}<0.001$ ). As the response here is log-transformed the magnitude of this effect is that, all else being equal, distance from homestead declined by approximately $10 \%$ for each hour.

Month also had a significant effect on the daytime proximity $\left(\mathrm{DP}_{\text {Adj }}\right)$ of cows to a protected area $\left(\mathrm{F}_{(11,7197)}=26.90, \mathrm{P}<0.001\right)$. The variability between months was very similar to that for $\mathrm{CPD}_{\mathrm{adj}}$. Cattle moved closest to the protected areas in the late growing season, while cattle were furthest from protected areas in the post-harvest season (Fig. 4).

The highest values for the MDD coincided with the lowest values for $\mathrm{CDP}_{\text {Adj }}$ (Fig. 4). A Spearman rank order correlation showed a significant negative relationship $\left(r_{s}=-0.99, \mathrm{P}<\right.$ 0.001, d.f. $=11$ ) between monthly mean $\mathrm{MDD}$ and $\mathrm{CDP}_{A d j}$ showing that when cows moved away from homesteads they moved towards the grazing areas close to the PA boundary. 


\subsection{Cattle herding patterns in relation to crop fields and woody cover}

Selection for crop fields by cattle varied significantly among months $\left(\right.$ RMANOVA, $\mathrm{F}_{(11,143)}=$ 3.45, $\mathrm{P}=0.014)$, with strongest selection during the post-harvest season and strongest avoidance during the late growing season (Fig. 4). Selection for crop fields was closely associated with the movements of herded cattle. Among months, the variation in selection for crop fields explained $83 \%$ of the variation in $\operatorname{MDD}\left(\mathrm{F}_{(1,10)}=48.57, \mathrm{P}<0.01, \mathrm{R}^{2}=0.829\right)$ and $72 \%$ of the variation in $\mathrm{CDP}_{A d j}\left(\mathrm{~F}_{(1,10)}=26.07, \mathrm{P}<0.01, \mathrm{R}^{2}=0.723\right)$. Avoidance of crop fields coincided with the months when cattle were herded furthest from their home enclosures and closest to a PA boundary (the late growing season), while the highest selection for crop fields coincided with those months when cattle were closest to home and furthest from PAs (the post-harvest season).

During the late growing season, selection by cattle for areas with highest woody cover $(20 \%$ and above) was stronger (i.e. cattle were herded into more woody areas), and selection for more open areas (0-10\%) was weaker than at other times of the year (Fig. 5). This contrasted with the post-harvest season, when cattle avoided woody areas and selected for (i.e. were herded into) open areas (Fig. 5).

\subsection{Seasonality in herd supervision and night-time cattle positions}

Across all cows and all months, $82.9 \%$ of midnight fixes were recorded within $30 \mathrm{~m}$ of the home enclosure. Thus, cattle spent an average of $17.1 \%$ of nights outside the safety of an enclosure. There was no seasonal variation in the percentage of nights spent by cattle within their home enclosures (online appendix Fig. A1). Throughout the year, an average of $10.1 \%$ of midnight fixes were recorded within the 30-100m distance-from-home-enclosure categories, while $2.4 \%$ and $4.3 \%$ were recorded in the $100 \mathrm{~m}-1 \mathrm{~km}$ and $>1 \mathrm{~km}$ categories 
respectively (online appendix Fig. A1). Cattle spoor were most commonly encountered on transects in the early growing season compared to the late growing or post harvest season (online appendix Fig. A2; $X^{2}=$ d.f.=2, $\mathrm{P}=0.013$ ). Conversely, human spoor were less commonly encountered in the early growing season and more common in the late growing and post-harvest season, though this difference was not significant $\left(X^{2}=\right.$ d.f. $\left.=2, \quad \mathrm{P}=0.09\right)$. Consequently the number of cattle present per person was significantly higher in the early growing season (online appendix Fig. A2; ratio of humans: cattle: early growing season: 1:7.3 \pm 3.5 ; late growing season: $1: 1.36 \pm 0.31$; Post-harvest season: $1: 0.99 \pm 0.66 ; \mathrm{KW}$ test, $X^{2}=$ d.f. $=2, \mathrm{P}=0.003)$. While we could not ascertain if people present were engaged in herding activities it seems likely that increased presence of people is likely to have been a deterrent to predators.

\subsection{Cattle movements and lion depredation incidents}

There was a significant positive correlation between the monthly means of the number of cattle killed and the MDD that cattle were herded from their home enclosures $(r=0.72, \mathrm{P}=$ 0.008, $\mathrm{df}=10$; online appendix Fig. A2). Across months, the correlation between the $\mathrm{CDP}_{\text {Adj }}$ of cattle to a PA boundary and the number of cattle killed was significant and negative $(r=-$ 0.65, P = 0.023, d.f. = 10; Fig. 6).

\section{Discussion}

This study investigated the extent to which seasonal herding patterns and traditional agropastoral practices contribute to the vulnerability of cattle to lion depredation. While carnivore movement patterns constitute a fairly well-studied dimension in the interactions between 
livestock and large carnivores (Valeix et al. 2012, Schuette et al. 2013, Oriol-Cotterill et al. 2015a, Oriol-Cotterill et al. 2015b), livestock movements are less frequently directly studied. The results presented here reveal a complex interplay between seasonality in agro-pastoral practices and human-carnivore conflict.

\subsection{Crop growing practices and cattle herding}

Cattle in Tsholotsho are herded from their home enclosures each morning to grazing pastures and move slowly back to their home enclosures, reaching these around sunset. Informal discussions with local herdsman revealed that while some remain with their cattle throughout the day, others leave their cattle unattended until they are located in the late afternoon. Spatio-temporal fluctuations in cattle herding patterns were shown to be closely associated with crop growing. Crop growing practices in many traditional agro-pastoral systems are seasonal because of reliance on rainfall. In Tsholotsho, crop growing extends through the wet summer months with ploughing taking place in October and November, planting in December and harvesting in April/May. Cattle movement data show that owners herd their stock away from crop fields (which are usually directly adjacent to villages) in the growing season, particularly the late growing season (February- May), to avoid crop damage. As the growing season progressed, cattle moved further from their home enclosures and closer to PAs, coinciding with the avoidance of arable fields. Planting times vary amongst villages depending on local rainfall which is often highly variable and spatially erratic (Guerbois et al. 2012) therefore avoidance of fields by cattle was more consistent among GPS collared cows later in the growing season when the majority of crop fields had been planted. After harvest, crop fields are left fallow for the post-harvest season (June to September). From early June, cattle owners are permitted (by sanction of local traditional leaders) to allow their cattle to roam freely in the harvested fields, where they feed on the crop residues. 
Selection for crop fields by cattle peaked in June, when cattle were permitted to enter the fallow fields, and remained high for the rest of the post-harvest season. Cattle remained closest to their home enclosures and furthest from PAs during the post-harvest season, when selection for fallow crop fields was highest.

The relatively high density of people in the Tsholotsho study area $\left(7.3\right.$ rural huts $\left./ \mathrm{km}^{2}\right)$, coupled with positioning of crop fields directly adjacent to villages, means that cattle needed to be herded further from their home enclosures each day during the growing season in order to avoid crops and find suitable grazing (Scoones 1995). The strong negative correlation between the monthly mean MDD and $\mathrm{CDP}_{A d j}$ values indicates that increases in the distance that cattle were herded from their home enclosures during the growing season were associated with movements towards the PAs in the North. The practice of herding cattle towards the PAs was driven by the availability of natural grazing in the informal buffer zone between community lands and Hwange National Park. Areas directly adjacent to the PA boundaries are largely maintained as a buffer zone between PA and village lands and have not been transformed or cultivated and these areas may thus provide grazing for cattle. By contrast, the density of homesteads and crop fields increases to the South and east of the study area distant from the PA boundaries. Thus, for those villages within $20 \mathrm{~km}$ of the PAs boundaries (i.e. all the villages at which we collared cattle) the best potential grazing may be found towards the PAs to the North of the study area. Informal discussions with local herdsmen confirmed that the herding of cattle towards the PAs is a strategy to find better grazing, limit grazing competition and avoid crop damage in neighbouring villages towards the south. 


\subsection{Seasonal depredation of cattle by lions: the role of wild prey availability}

While some studies suggest carnivores raid livestock more frequently in the dry season (Butler 2000) our results indicate the opposite trend, which is in accord with a number of previous studies in Africa which recorded elevated rates of livestock depredation during the wetter months (Patterson et al. 2004, Woodroffe and Frank 2005, Kolowski and Holekamp 2006). Regardless of wet or dry season depredation peaks, all these studies suggest an increase in the frequency of livestock depredation in times of wild prey scarcity (Bagchi and Mishra 2006, Valeix et al. 2012).

In HNP, the distribution of wild herbivores is constrained by the distribution of surface water and lions tend to take prey closer to water than expected from a random distribution of kills (Valeix et al. 2009, Davidson et al. 2012). In the dry season, wild prey are more predictably distributed in the landscape (in close proximity to limited water sources) and are more likely to be suffering from seasonal nutritional stress, making them more available as prey (Owen-Smith and Mills 2008, Davidson et al. 2012). In contrast, during the wet season water is more freely available and widely distributed in scattered seasonal pans and hence wild prey species are more dispersed in the landscape and in better condition, making them harder to find and kill (Patterson et al. 2004). For example, buffalo (Syncerus caffer), an important prey species for lions in HNP, are often in better condition during the wet season, making them more challenging for lions to kill (Owen-Smith and Mills 2008).. Thus, lions may be predisposed to switch to livestock as an alternative food source in the wet season (Woodroffe and Frank 2005, Kolowski and Holekamp 2006, Valeix et al. 2012). In the Makgadikgadi system of Botswana, radio-collared lions on the park periphery preferentially preyed on migratory wild herbivores when they were present in their home ranges. Here,

when herds migrated, most lions remained resident at the PA boundary and switched to 
Livestock herding patterns influence vulnerability to lion depredation

feeding on abundant and readily available livestock during these periods of wild prey scarcity (Valeix et al. 2012).

\subsection{Seasonal depredation of cattle by lions: the role of cattle herding}

A number of studies suggest that livestock husbandry techniques influence the likelihood of conflict with carnivores (Mishra 1997, Ogada et al. 2003, Wang and Macdonald 2006). Our results suggest that seasonality in cattle herding practices influences the vulnerability of cattle to depredation. Wang \& Macdonald (2006) found that herdsmen in Bhutan who grazed their livestock closer to villages suffered fewer losses to predators than those who grazed their animals in distant pastures. Other studies have also found that livestock which graze further from villages (e.g. Mishra 1997) and closer to protected/forested areas (Conforti and Azevedo 2003, Hemson et al. 2009) are more vulnerable to predation by wild carnivores. In farmland close to Chirisa Safari Area (Zimbabwe) and Khutse Game Reserve (Botswana), livestock depredation by lions and leopards was higher closer to the boundaries of the respective PAs (Butler 2000, Schiess-Meier et al. 2007).

Variation in the availability of wild prey and seasonality in the movements of herded cattle may coincide to create a period of high vulnerability for cattle in the growing (wet) season, particularly the late growing season. Lions killed more cattle in the late growing season, when cattle were herded furthest from their home enclosures and closest to PAs, and when the probability that lions were seeking alternative prey was most likely to be highest. Lions killed fewer cattle in the post-harvest (dry) season, when cattle remained closest to their home enclosures and at greater distances from the PA. Furthermore, wild prey availability was likely highest at this time (Loveridge et al. 2009, Davidson et al. 2012). 
The higher vulnerability of cattle to lion depredation during the crop growing season may have been further increased by two additional factors. Firstly, using the ratio of cattle to human spoor as proxy for levels of cattle supervision, we suggest that fewer encounters of people and more encounters of cattle in surveys during the early growing season (OctoberJanuary) is indicative of lower levels of livestock supervision in grazing areas at this time. During this period, ploughing, planting and tending of crops place heavy demands on people's time and energy that this is likely to limit manpower and time available to guard grazing livestock. Secondly, cattle used areas of higher woody cover close to the PA boundary during the late growing season. Lions are ambush predators and it is likely that more wooded areas provide cover, thereby facilitating predation on cattle. Similarly, livestock depredation by pumas Puma concolor and jaguars Panthera onca in southern and central Brazil, was more frequent in wooded habitats (Mazzolli et al. 2002, Palmeira et al. 2008). Lions may also prefer to hunt in areas of greater woody cover because of reduced risk of encountering humans (Valeix et al. 2012). During the post-harvest season, cattle avoided woody areas and selected for more open areas, and this may have further reduced their vulnerability to lion depredation at this time.

\subsection{A landscape of fear for lions}

Ogada et al. (2003) found the probability of lion attacks on livestock was significantly reduced with increasing levels of human activity. We suggest that the proximity to human activity, and potentially better supervision of grazing cattle, deters lions from killing cattle in areas around villages where they are most abundant. Outside PAs, lions have been shown to make a variety of behavioural adjustments to reduce the chance of encountering people and hence the risk of anthropogenic mortality (Mogensen et al. 2011, Valeix et al. 2012, OriolCotterill et al. 2015a). Schuette et al. (2013) showed that lions shifted their movements 
towards a protected refuge to avoid contact with seasonally-shifting human settlements. In the areas adjacent to HNP, direct persecution by humans is a significant source of mortality for lions, with higher mortality observed in areas where livestock losses are most severe (Loveridge et al. 2010a). Thus, lions are likely to face a 'landscape of fear' as they move from the PA into surrounding communal lands and must balance the benefits of accessing livestock with the risks of being killed by humans.

Our data show that where the majority of conflict incidents were recorded within $2.5 \mathrm{~km}$ of the boundary of a PA, despite collared cattle spending the majority of their time further than $2.5 \mathrm{~km}$ from PAs. Few depredation incidents were recorded within $500 \mathrm{~m}$ of the closest homestead, even though cattle spent the majority of their time within this distance to homesteads. It follows that it is less risky for lions to attack cattle when they are further from homesteads and closer to PAs and this may largely explain the observed wet season depredation peak.

\subsection{Seasonal cattle movements and night-time depredation}

While lions occasionally attack livestock by jumping into enclosures (Ogada et al. 2003, Kolowski and Holekamp 2006), our data show that lions in Tsholotsho mostly take cattle opportunistically on those nights when they are left out of their protective enclosures. Nocturnal hunting and activity patterns of lions outside PAs may also be a further strategy to avoid spatial and temporal overlap with human activity (Valeix et al. 2012, Oriol-Cotterill et al. 2015a). Herdsmen who do not remain with their cattle throughout the day may fail to fetch cattle returning from their day-time pasture. We found that $17 \%$ of midnight cattle positions were situated outside the home enclosure and just over $4 \%$ were more than a kilometre away. 
This suggests that, on average, collared cattle were inadequately protected in the enclosure on around 60 nights of the year. The costs of failure to bring cattle home would be greatest in the growing season when cattle are herded further from their home enclosures and closer to PAs.

\subsection{Implications for future management}

Carnivore conservation inevitably incorporates human socio-political, cultural and behavioural- ecological dimensions (Treves and Karanth 2003). Large carnivores such as lions are highly valued globally as conservation icons, but often have little or even negative value at the local scale due to the significant economic costs they impose on the lives of the people who live alongside them (Hemson et al. 2009, Dickman 2010). While improved husbandry techniques may reduce conflict, the best strategy for conflict prevention is the translation of the global value of carnivores to tangible benefits for local people. In reality, this is difficult to achieve and whilst political and local elites often benefit from Community Based Natural Resource Management (CBNRM) programmes (such as CAMPFIRE in Zimbabwe) impoverished rural people frequently derive little material benefit (Murombedzi 1999). The most promising solution to solving human-predator conflict is improved livestock protection (Hazzah et al. 2014, Lichtenfeld et al. 2015) and, where practical, separation of predators and people, through interventions such as fencing (Packer et al. 2013).

In this study, the vulnerability of cattle to lion depredation varied seasonally and management strategies must be designed with this in mind. While the availability of wild prey may be an important driver of lion predation, it cannot be controlled and mitigation attempts would do better to address the role of cattle herding patterns as a determinant of seasonal vulnerability. Enhanced husbandry and herding practices should focus on the critical times when livestock losses are greatest, namely over the growing season in the wet months of the year. Altering 
herding practices at this time to reduce vulnerability to lion depredation would involve strategies that attempt to minimize: (1) the distance that cattle move from their home enclosures and (2) the proximity of cattle to PAs. However, the seasonal cropping practices that push cattle into risky areas during the growing season are integral to traditional agricultural practices within the community and could be difficult to alter.

Efforts are perhaps better directed at the wider use of protective enclosures and better supervision and protection of grazing livestock during the wet season. Our results suggest that lions around HNP selectively kill cattle away from protective enclosures (or homesteads in general) and at night, as was found in Botswana (Hemson et al. 2009, Valeix et al. 2012). Thus, while cattle spend $83 \%$ of nights within their home enclosures, they are vulnerable to lions for around 60 nights of the year. More efficient rounding up of cattle for the night might therefore limit losses and efforts should primarily be directed at the growing season when cattle are grazed in more vulnerable areas. Nevertheless, it is important to acknowledge that the demands of tending crops in the wet season may place significant constraints on people's ability to adequately supervise livestock. Possible strategies to improve livestock protection could be communal herding and protection of herds, thus sharing the responsibility between several families. Mobile communal enclosures (bomas) have the potential to be used when livestock need to access grazing distant from villages or be kept away from crop fields.

\section{Acknowledgements}

We thank acting Chief Mlevu and Chief Nelukoba-Dingani and the District Administrators of Hwange and Tsholotsho Rural District Councils for their permission to undertake this study. We thank the village heads and people of Ngamo, Vozheka, Tshefutshefu, Siwela, Ziga, 
Livestock herding patterns influence vulnerability to lion depredation

Mlevu, Manjelengwa, Mhlabeni, Vulashaba, Ndodana, Emanaleni, Sodaka, Makeni, Bemba and Mangutana villages for permission to collar cattle and assistance in subsequent monitoring. We thank the people of the Tsholotsho community for facilitating the study and their assistance in monitoring livestock depredation and acknowledge the support of the ZPWMA in this and ongoing research. This research was funded by Recanati-Kaplan, Rufford Maurice-Laing, RG Frankenberg Foundations and Panthera. Project sponsors had no role in study design, data collection, analysis or interpretation. We thanks two anonymous reviewers for their helpful input and advice. 


\section{References}

Bagchi, S. and C. Mishra. 2006. Living with large carnivores: predation on livestock by the snow leopard (Uncia uncia). Journal of Zoology 268:217-224.

Bauer, H., C. Packer, P. J. Funston, P. P. Henschel, and K. Nowell. 2015. Panthera leo. The IUCN Red List of Threatened Species. Version 2015.2. www.iucnredlist.org. Downloaded 14 July 2015.

Butler, J. R. A. 2000. The economic costs of wildlife predation on livestock in Gokwe communal land, Zimbabwe. African Journal of Ecology 38:23-30.

Calenge, C. 2006. The package 'Adehabitat' for the R software: a tool for the analysis of spce and habitat use by animals. Ecological Modelling 197:516-519.

Cardillo, M., A. Purvis, W. Sechrest, J. L. Gittleman, J. Bielby, and G. M. Mace. 2004. Human density and extinction risk in the world's carnivores. PloS Biology 2:0909 - 0914 . http://biology.plosjournals.org.

Conforti, V. A. and F. C. C. Azevedo, de. 2003. Local perceptions of jaguars (Panthera onca) and pumas (Puma concolor) in the Iguaçu National Park area, south Brazil. Biological Conservation 111:215-221.

Davidson, Z., M. Valeix, A. J. Loveridge, J. E. Hunt, P. J. Johnson, H. Madzikanda, and D. W. Macdonald. 2012. Environmental determinants of habitat and kill site selection in a large carnivore: scale matters. Journal of Mammalogy 93.

Dickman, A. 2010. Complexities of conflict: the importance of considering social factors for effectively resolving human-wildlife conflict. Animal Conservation 13:458-466.

Faraway, J. J. 2005. Extending the linear model with R: generalised linear, mixed effects and nonparametric regression models. CRC Press.

Frank, L., G. Hemson, H. Kushnir, and C. Packer. 2006. Lions conflict and conservation in east and southern Africa. IUCN, Eastern and southern Africa lion conservation workshop, Johannesburg.

Guerbois, C., E. Chapanda, and H. Fritz. 2012. Combining multi-scale socio-ecological approaches to understand the susceptability of subsistence farmers to elephant crop raiding on the edge of a protected area. Journal of Applied Ecology 49:1149-1158.

Hansen, M., R. DeFries, J. R. Townshend, R. Sohlberg, C. Dimiceli, and M. Carroll. 2002. Towards an operational MODIS continuous field of percent tree cover algorithm: examples using AVHRR and MODIS data. . Remote Sens. Environ. 83:303-319.

Hazzah, L., S. Dolrenry, L. Naughton-Treves, C. Edwards, O. Mwebi, F. Kearny, and L. Frank. 2014. Efficacy of two lion conservation programs in Maasiland, Kenya. Conservation Biology 28:851-860. 
Hemson, G., S. D. Maclennan, G. Mills, P. J. Johnson, and D. W. Macdonald. 2009. Community, lions, livestock and money: A spatial and social analysis of attitudes to wildlife and the the conservation value of tourism in human-carnivore in Botswana. Biological Conservation 142.

Inskip, C. and A. Zimmermann. 2009. Human-felid conflict: a review of the patterns and priorities worldwide. Oryx 43.

IUCN-SSC. 2006. Conservation strategy for the lion Panthera leo in eastern and southern Africa. IUCN SSC Cat Specialist Group, www.felidae.org.

Jacobs, J. 1974. Quantitative measurement of food selection. Oecologia 14:413-417.

Kolowski, J. M. and K. E. Holekamp. 2006. Spatial, temporal, and physical characteristics of livestock depredation by large carnivores along a Kenyan reserve border. Biological Conservation 128:529-541.

Laver, P. N. and M. J. Kelly. 2008. A Critical Review of Home Range Studies. Journal of Wildlife Management 72:290-298.

Lichtenfeld, L., C. Trout, and E. Kisimir. 2015. Evidence-based conservation:predator-proof bomas protect livestock and lions. Biodiversity and Conservation 24:483-491.

Loveridge, A. J., G. Hemson, Z. Davidson, and D. W. Macdonald. 2010a. African lions on the edge: Reserve boundaries as 'attractive sinks'. Pages 283- 304 in D. W. Macdonald and A. J. Loveridge, editors. Biology and Conservation of Wild Felids. Oxford University Press, Oxford.

Loveridge, A. J., M. Valeix, Z. Davidson, F. Murindagomo, H. Fritz, and D. W. Macdonald. 2009. Changes in home range size of African lions in relation to pride size and prey biomass in a semi-arid savanna. Ecography 32:1-10.

Loveridge, A. J., S. W. Wang, L. G. Frank, and J. Seidensticker. 2010b. People and wild felids: conservation of cats and management of conflicts. Pages 161-196 in D. W. Macdonald and A. J. Loveridge, editors. Biology and Conservation of Wild Felids. Oxford University Press, Oxford.

Macdonald, D. W., A. J. Loveridge, and A. Rabinowitz. 2010. Felid futures: crossing disciplines, borders, and generations. Pages 599-653 in D. W. Macdonald and A. J. Loveridge, editors. Biology and Conservation of Wild Felids. Oxford University Press, Oxford.

Mazzolli, M., M. E. Graipel, and N. Dunstone. 2002. Mountain lion depredation in southern Brazil. Biological Conservation:43-51.

Mishra, C. 1997. Livestock depredation by large carnivores in the Indian trans-Himalaya: conflict perceptions and conservation prospects. Environmental Conservation 24:338-343.

Mogensen, N. L., J. O. Ogutu, and T. Dabelsteen. 2011. The effects of pastoralism and protection on lion behaviour, demography and space use in the Mara Region of Kenya. African Zoology 46:78-87. 
Murombedzi, J. C. 1999. Devolution and stewardship in Zimbabwe's campfire programme. Journal of International Development 11:287-293.

Ogada, M. O., R. Woodroffe, N. O. Oguge, and L. G. Frank. 2003. Limiting depredation by African carnivores: the role of livestock husbandry. Conservation Biology 17:1521-1530.

Oriol-Cotterill, A., D. W. Macdonald, M. Valeix, S. Ekwanga, and L. G. Frank. 2015a. Spatiotemporal patterns of lion space use in a human dominated landscape. Animal Behaviour 101:27-39.

Oriol-Cotterill, A., M. Valiex, L. Frank, C. Riginos, and D. W. Macdonald. 2015b. Landscapes of coexistence for terrestrial carnivores: the ecological consequences of being downgraded from ultimate to penultimate predator by humans. Oikos DOI: 10.1111/oik.02224.

Owen-Smith, N. and M. Mills. 2008. Shifting prey selection generates contrasting herbivore dynamics within a large-mammal predator-prey web. Ecology 89:1120-1133.

Packer, C., A. J. Loveridge, S. Canney, T. Caro, S. T. Garnett, M. L. Pfeifer, K. K. Zander, A. Swanson, D. MacNulty, G. A. Balme, H. Bauer, C. M. Begg, K. S. Begg, S. Bhalla, C. Bissett, T. Bodasing, H. Brink, A. Burger, A. C. Burton, B. Clegg, S. Dell, A. Delsink, T. Dickerson, S. M. Dloniak, D. Druce, L. Frank, P. J. Funston, N. Gichohi, R. J. Groom, C. Hanekom, B. Heath, L. T. B. Hunter, H. DeIongh, C. J. Joubert, S. M. Kasiki, B. M. Kissui, W. Knocker, B. Leathem, P. A. Lindsey, S. D. Maclennan, J. W. McNutt, S. M. Miller, S. Naylor, P. Nel, C. Ng'weno, K. Nicholls, J. O. Ogutu, E. Okot-Omoya, B. D. Patterson, A. Plumptre, J. Salerno, K. Skinner, R. Slotow, E. A. Sogbohossou, K. Stratford, C. Winterbach, H. Winterbach, and S. Polasky. 2013. Conserving Large Carnivores: Dollars and Fence Ecology Letters 16:635-641.

Palmeira, F. B. L., P. G. Crawshaw, C. M. Haddad, K. M. Ferraz, and L. M. Verdade. 2008. Cattle depredation by puma (Puma concolor) and jaguar (Panthera onca) in central-western Brazil. Biological Conservation 141:118-125.

Patterson, B. D., S. M. Kasiki, E. Selempo, and R. W. Kays. 2004. Livestock predation by lions (Panthera leo) and other carnivores on ranches neighbouring Tsavo National Park, Kenya. Biological Conservation 119:507-516.

Periquet, S. 2014. Sharing the top: how do spotted hyaenas cope with lions? University of Lyon, Lyon, France.

Pinheiro, J. C. and D. M. Bates. 2000. Mixed effects models in S and S-PLUS. Springer, New York, London.

Pinheiro, J. C., D. M. Bates, S. DebRoy, D. Sarkar, and R-Core-Team. 2014. _nlme: linear and Nonlinear Mixed Effects Models_. R Package version 3.1-117, <URL: http://CRAN.Rproject.org/package $=$ nlme $>$.

R_Core_Team. 2012. R: A language and environment for statistical computing.in R. F. f. S. Computing, editor. ISBN 3-900051-07-0, URL http://www.R-project.org/, Vienna, Austria. 
Schiess-Meier, M., S. Ramsauer, T. Gabanapelo, and B. Konig. 2007. Livestock Predation - insights from problem animal control registers in Botswana. Journal of Wildlife Management 71:1267-1274.

Schuette, P., S. Creel, and D. Christianson. 2013. Coexistence of African lions, livestock and people in a landscape with variable human land use and seasonal movements. Biological Conservation 157:148-154.

Scoones, I. 1995. Exploiting herterogeneity:habitat use by cattle in dryland Zimbabwe. Journal of Arid Environments 29.

Treves, A. and K. U. Karanth. 2003. Human-carnivore conflict and perspectives on carnivore management worldwide. Conservation Biology 17:1491-1499.

Valeix, M., G. Hemson, A. J. Loveridge, G. Mills, and D. W. Macdonald. 2012. Behavioural adjustments of a large carnivore to access secondary prey in a human dominated landscape. Journal of Applied Ecology 49:73-81.

Valeix, M., A. J. Loveridge, S. Chamaillé-Jammes, Z. Davidson, F. Murindagomo, H. Fritz, and D. W. Macdonald. 2009. Behavioural adjustments of African herbivores to predation risk by lions: Spatiotemporal variations influence habitat use. Ecology 90:23-30.

Wang, S. W. and D. W. Macdonald. 2006. Livestock predation by carnivores in Jigme Singye Wangchuck National Park, Bhutan. Biological Conservation 129:558-565.

Woodroffe, R. and L. G. Frank. 2005. Lethal control of African lions (Panthera leo): local and regional population impacts. Animal Conservation 8:91-98.

Woodroffe, R. and J. R. Ginsberg. 1998. Edge effects and the extinction of populations inside protected areas. Science 280:2126-2128. 
Livestock herding patterns influence vulnerability to lion depredation

Figure 1

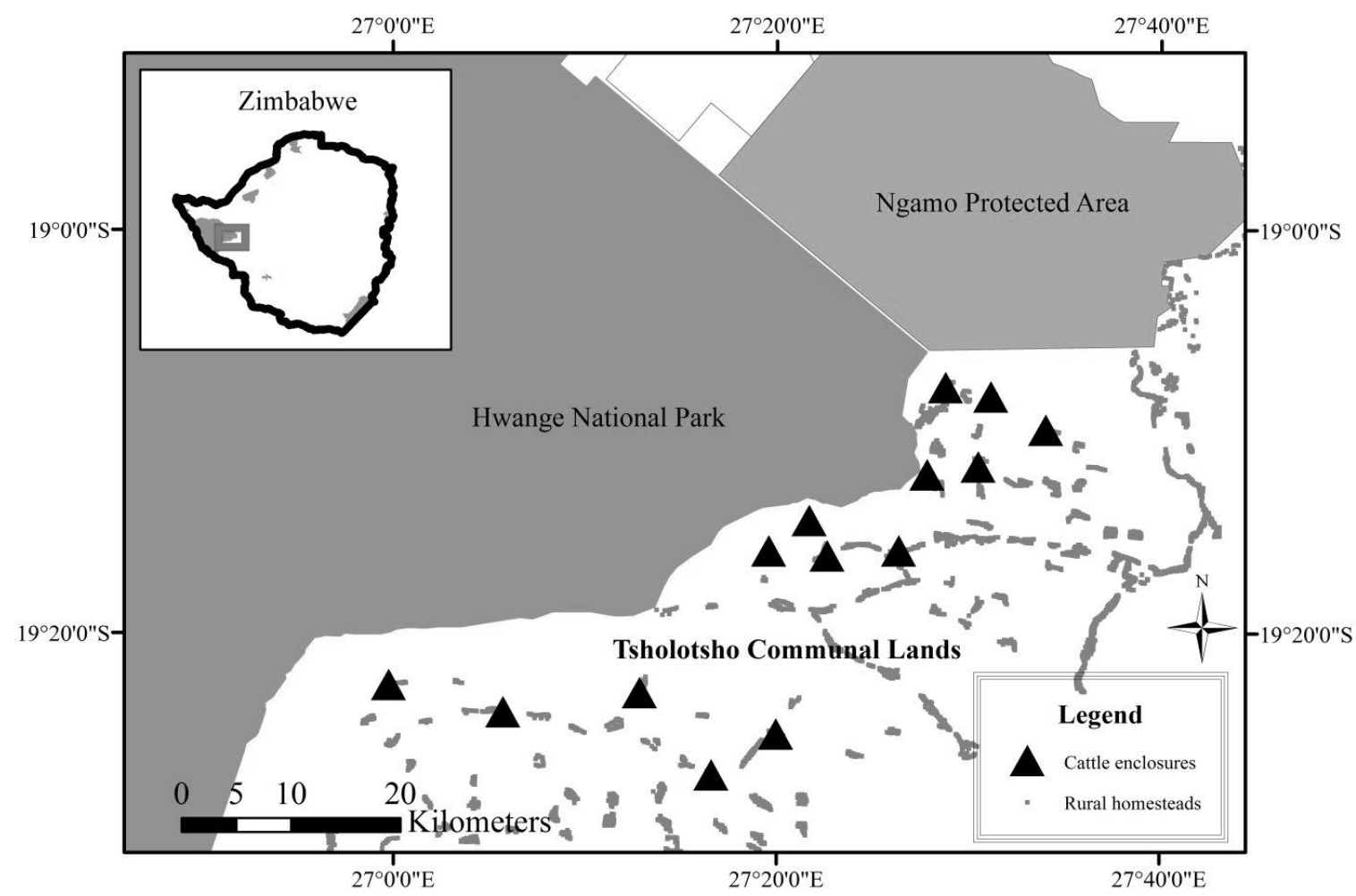

Figure 1. The Tsholotsho study area, showing the positions of cattle enclosures in the villages at which cattle GPS collars were deployed (one collared cow per village). Rural homesteads mapped from satellite imagery are also shown (Google Earth 2013). 
Figure 2

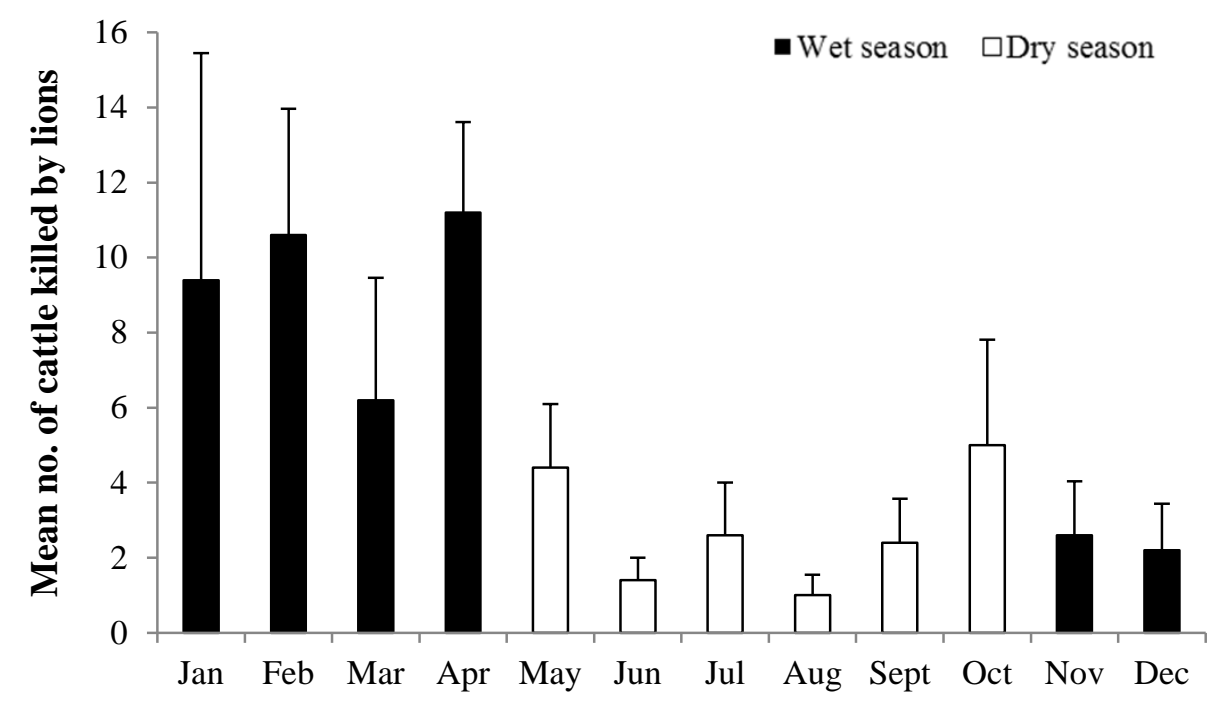

Figure 2. The mean number of cattle ( $\mathrm{N}=5$ years) killed by lions per month in Tsholotsho Communal Land between 2008 and 2012. Error bars represent standard error. 
Livestock herding patterns influence vulnerability to lion depredation

Figure 3

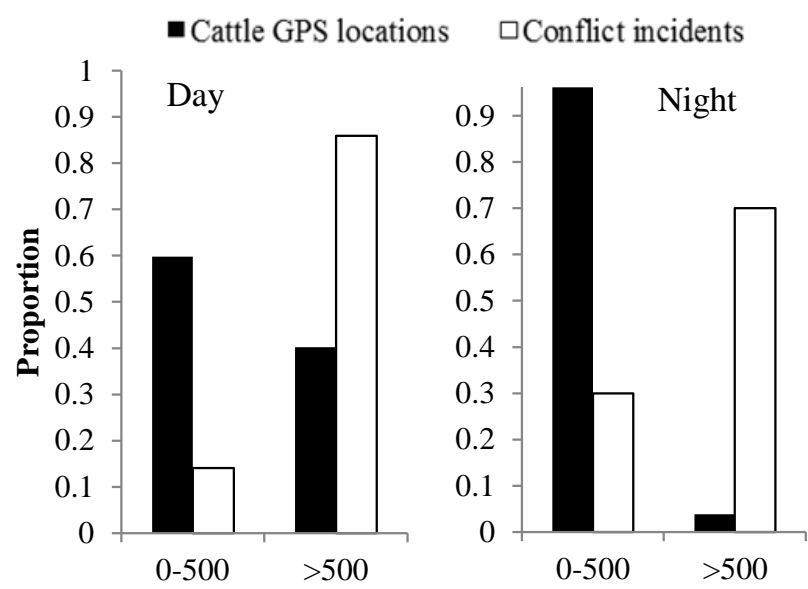

Distance to closest homestead (m)

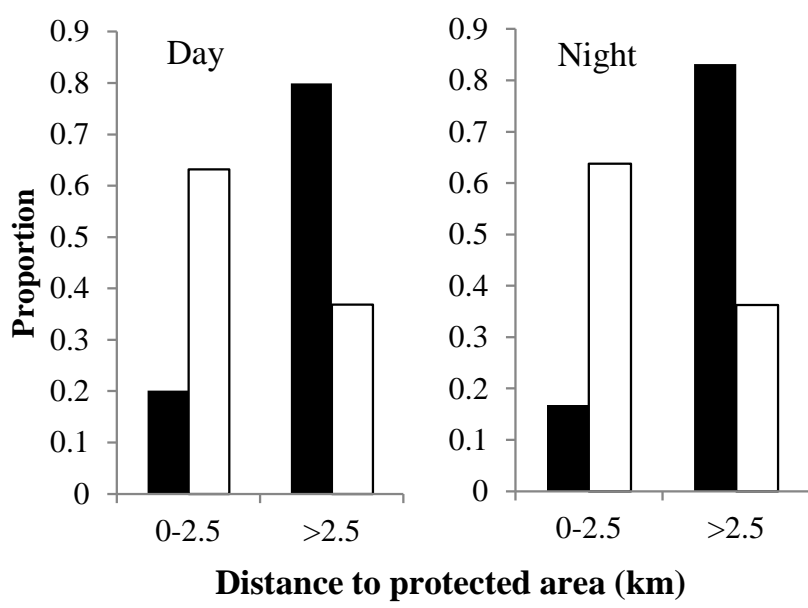

Figure 3. A comparison between the proportion of lion-cattle conflict incidents (2008-2012) and the proportion of cattle GPS fixes (2010-2012) in different distance-to-closest-homestead (top) and distance-to-protected-area categories (below). All GPS locations across all the collared cattle were used (2010 - 2012). Data are stratified by day $(\mathrm{N}=58$ conflict incidents, $\mathrm{N}=89961$ cattle locations) and night ( $\mathrm{N}=80$ conflict incidents, $\mathrm{N}=82932$ cattle locations). 
Figure 4

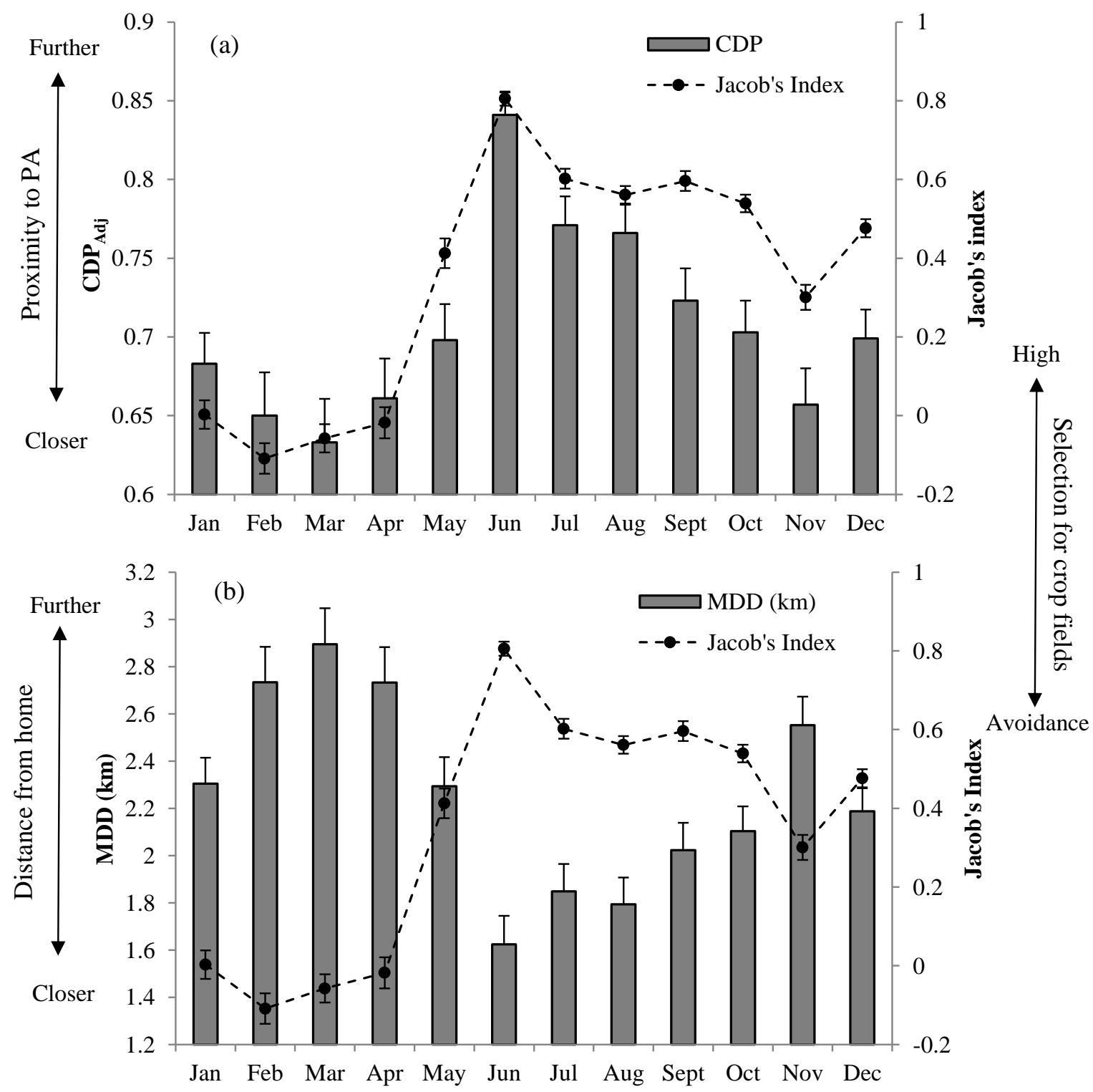

Figure 4. (a) The mean adjusted closest daily proximity $\left(\mathrm{CDP}_{A d j}\right)$ of cattle to a PA boundary and (b) The mean maximum daily distance (MDD) travelled by cattle from their home enclosures $(\mathrm{N}=14$ cattle). The monthly relationship between selection for crop fields by cattle (Jacob's Index) and each of $\mathrm{CDP}_{\text {Adj }}$ and MDD is shown by the dotted line graphs. Data for MDD and $\mathrm{CDP}_{A d j}$ are averaged over all daily values for all cows (N=7224 observations). Error bars represent $95 \%$ confidence intervals for $\mathrm{MDD}$ and $\mathrm{CDP}_{\mathrm{Adj}}$ and standard error for the Jacob's Index. 
Figure 5

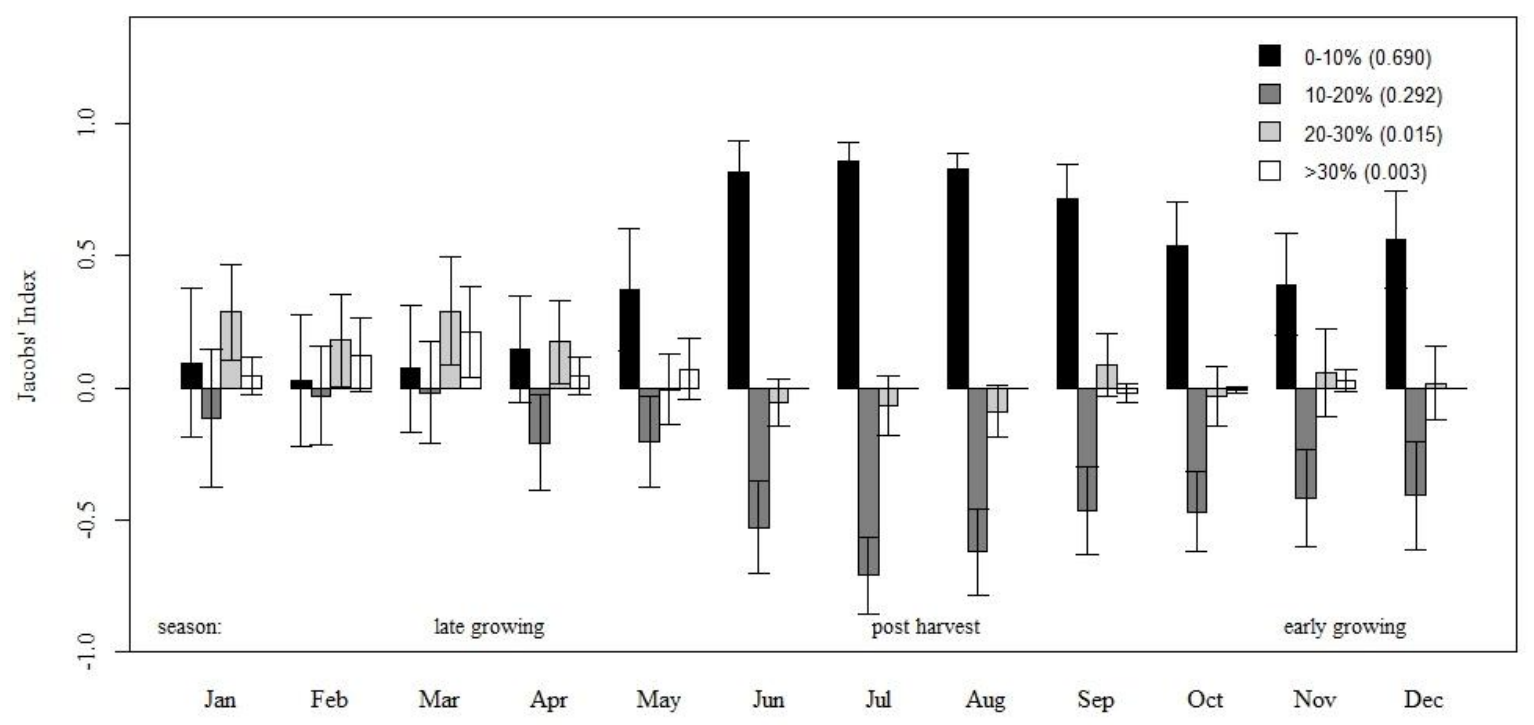

Figure 5. Seasonal variation in the selection by cattle (mean Jacobs' Index) of four 'percentage woody cover' habitat categories. Error bars represent $90 \%$ confidence intervals. Values in brackets in the legend represent the mean proportion of each habitat category in all cattle home ranges $(\mathrm{N}=14$ cattle). 
Figure 6
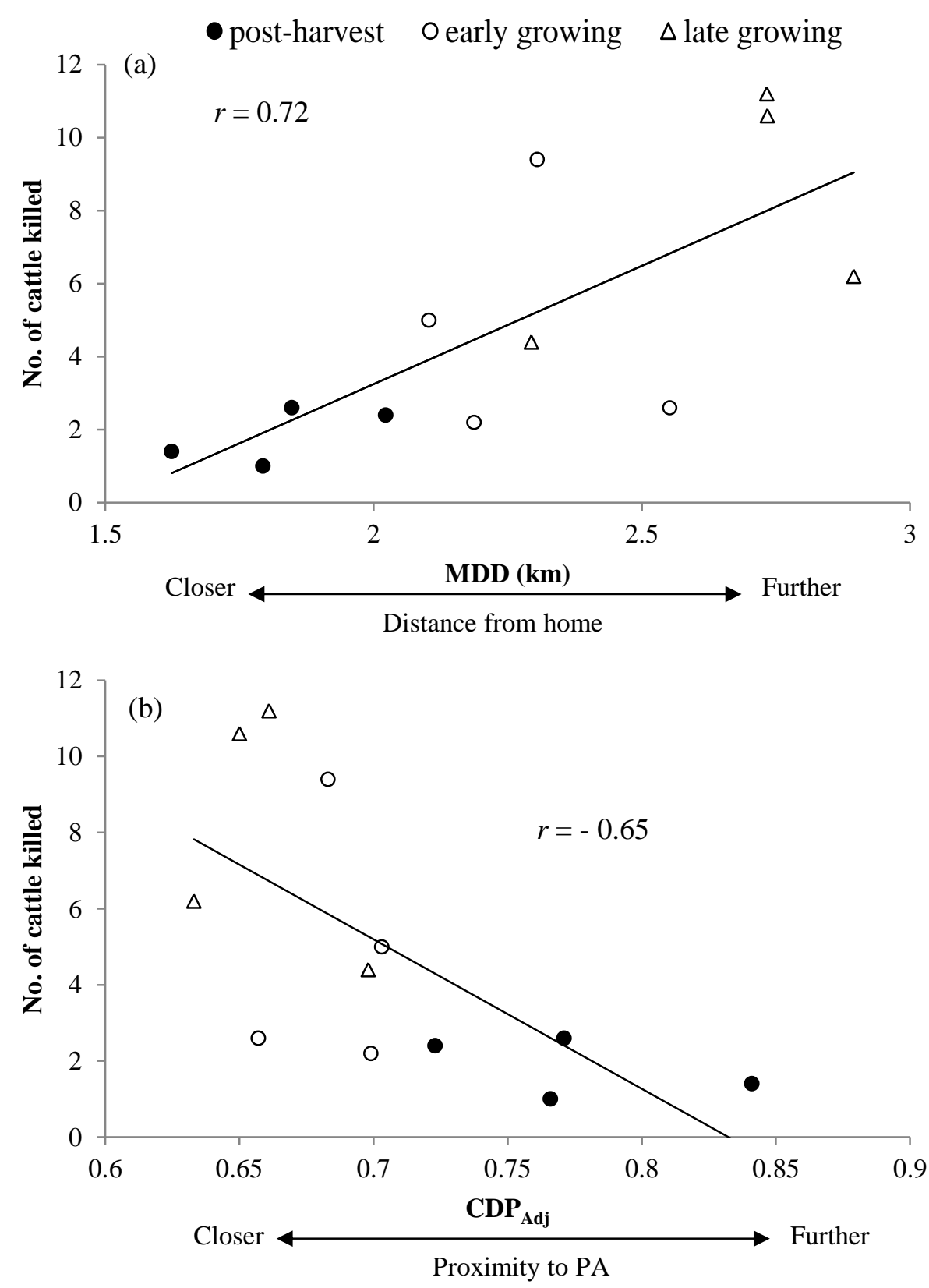

Figure 6. (a) The association between the monthly mean maximum daily distance (MDD) travelled by cattle from their home enclosures $(2010-2012)$ and the monthly mean $(\mathrm{N}=5$ years) number of cattle killed by lions $(2008-2012)$. (b) The association between the monthly mean adjusted closest daily proximity $\left(\mathrm{CDP}_{A d j}\right)$ of cattle to a PA boundary and the monthly mean ( $\mathrm{N}=5$ years) number of cattle killed by lions for the same time periods. 